\title{
Smooth coping: an embodied, Heideggerian approach to dual-process theory
}

Adaptive Behavior

$1-16$

(C) The Author(s) 2021

Article reuse guidelines:

sagepub.com/journals-permissions

DOI: I0.1।77//0597/2321/017337

journals.sagepub.com/home/adb

@SAGE

\section{Zachariah A Neemeh}

\begin{abstract}
Dual-process theories divide cognition into two kinds of processes: Type I processes that are autonomous and do not use working memory, and Type 2 processes that are decoupled from the immediate situation and use working memory. Often, Type I processes are also fast, high capacity, parallel, nonconscious, biased, contextualized, and associative, while Type 2 processes are typically slow, low capacity, serial, conscious, normative, abstract, and rule-based. This article argues for an embodied dual-process theory based on the phenomenology of Martin Heidegger. According to Heidegger, the basis of human agents' encounters with the world is in a prereflective, pragmatically engaged disposition marked by readiness-to-hand (Zuhandenheit), sometimes equated with "smooth coping." Examples of smooth coping include walking, throwing a ball, and other embodied actions that do not require reflective thought. I argue that smooth coping primarily consists of Type I processes. The Heideggerian dual-process model yields distinctly different hypotheses from Hubert Dreyfus' model of smooth coping, and I will critically engage with Dreyfus' work.
\end{abstract}

\section{Keywords}

Dual-process theory, embodied cognition, Hubert Dreyfus, Martin Heidegger, smooth coping

Handling Editor: Dr. Massimiliano Cappuccio, University of New South Wales, Australia

\section{Introduction}

Since their introduction in the 1970s, dual-process theories have been developed in several fields, including cognitive psychology (Sloman, 1996; Wason \& Evans, 1974), social psychology (Chaiken, 1980; Devine, 1989), behavioral economics (Kahneman, 2011; Kahneman \& Frederick, 2002), and the philosophy of mind (Carruthers, 2006; Dennett, 1991; Frankish, 2004). Their basic premise is that human reasoning is split into two discrete classes of processes: Type 1 or intuitive processes are autonomous and don't require working memory, while Type 2 or reflective processes are decoupled from the immediate situation and require working memory (Evans \& Stanovich, 2013). Some researchers in embodied cognition have begun to look to dual-process theory to argue that embodied action is Type 1 or it constitutes a novel type altogether (S. E. Dreyfus, 2014; Furley et al., 2015; Körner \& Strack, 2018; Petracca, 2020).

This article argues for an embodied dual-process theory based on the work of the phenomenologist Martin
Heidegger and recent embodied cognitive science. I argue that the collection of Type 1 processes exceeds the bounds of the brain and is embodied through the parallel networks of the peripheral nervous system and musculature. Although several embodied dual-process theories focus on how the body influences dual-process cognition (Körner \& Strack, 2018; Petracca, 2020), this article instead focuses on ways that the physiological body is constitutively part of many Type 1 processes. More specifically, smooth coping primarily consists of Type 1 processes. Smooth coping is a catch-all term for embodied action such as walking, running, grasping, or skiing, and is distinguished from more intentionally controlled action, as you might find in a novice learning

Department of Philosophy and Institute for Intelligent Systems, The University of Memphis, Memphis, TN, USA

\section{Corresponding author:}

Zachariah A Neemeh, Department of Philosophy and Institute for Intelligent Systems, The University of Memphis, Memphis, TN 38I52, USA.

Email: zaneemeh@memphis.edu 
Table I. A summary of Type I and Type 2 processes. From Evans and Stanovich (2013, p. 225), this list is an influential account, though not all dual-process theorists would accept every item (Evans, 2008).

\begin{tabular}{ll}
\hline Type I & Type 2 \\
\hline $\begin{array}{l}\text { Defining features } \\
\text { Does not require } \\
\text { working memory }\end{array}$ & Requires working memory \\
Autonomous & $\begin{array}{l}\text { Cognitive decoupling; } \\
\text { mental simulation }\end{array}$ \\
Typical correlates & Slow \\
Fast & Capacity limited \\
High capacity & Serial \\
Parallel & Conscious \\
Nonconscious & Normative responses \\
Biased responses & Abstract \\
Contextualized & Rule-based \\
Associative & Consequential decision \\
Experience-based & making \\
decision making & Correlated with cognitive \\
Independent of & ability \\
cognitive ability & \\
\hline
\end{tabular}

to drive. Phenomenologists consider smooth coping to be a basic, background mode of human activity (Merleau-Ponty, 1945/2012). My claim is that smooth coping is predominantly a Type 1 phenomenon. My argument has two central components:

1. Embodied action or smooth coping involves the defining features of Type 1 processes (autonomy and no working memory requirement) and many of its typical correlates (see Table 1).

2. Smooth coping is, therefore, primarily a Type 1 process (although Type 2 processes can also play a role, such as in expert action).

I begin by introducing dual-process theory (Section 2). I then introduce Martin Heidegger's phenomenology of embodied action or smooth coping (Section 3). Finally, I develop the outlines of my embodied dualprocess account (sections 3.1-3.5), several elements of which are based on Heidegger's phenomenology. My embodied dual-process model will also yield different hypotheses from Dreyfus' model of smooth coping (e.g. Section 3.3).

\section{Type I and Type 2 processes}

Type 1 and Type 2 processes are each a class of cognitive processes characterized by markedly different features. Type 1 processes are defined by being autonomous and not requiring working memory, and are often characterized as fast, parallel, nonconscious, and associative (Evans \& Stanovich, 2013). They are intuitive and are involved in the kinds of rapid and implicit judgments people make, for example, when judging someone's looks. They are autonomous in that they don't require reflection; for example, judging someone based on stereotypes is automatic, and the process itself can't be rationally vetoed (Devine, 1989). Type 2 processes are defined by a relative cognitive decoupling from the immediate context, as well as by requiring working memory. These processes are reflective rather than intuitive. Often, they are slow, serial, conscious, and rule-based.

The only essential features are requiring (or not) working memory and either autonomy or cognitive decoupling. However, the correlates can be understood as typical ways that Type 1 and Type 2 attributes cluster (Evans, 2008; Samuels, 2009). This nonrigid alignment alleviates many of the critiques that have been leveled against dual-process theories (Pennycook et al., 2018), particularly that they posit an inflexible and starkly dualistic view of mind (Bargh, 1994; Melnikoff $\&$ Bargh, 2018). Some dual-process theorists take the two kinds of mental processes to form two distinct cognitive systems (e.g. Sloman, 1996), sometimes called "System 1" and "System 2." Samuels (2009) calls this the "Token Thesis": each kind is a token of a cognitive system. The alternative is the "Type Thesis": each kind marks a type of cognitive process, but there are many tokens of these types. In agreement with Samuels and Evans and Stanovich (2013), I assume the Type Thesis is the more plausible option. Given that the brain is composed of such a diversity of subsystems, it is hard to see how plausibly to divide the mind into only two systems. Type 1 processes are typically the default, and Type 2 processes may intervene when called for (Stanovich, 2011). Alternatively, they may both be pervasively active (De Neys, 2017). Stereotypes, for example, characteristically involve Type 1 processes, while mathematical reasoning characteristically involves Type 2 processes. Nonetheless, stereotypes may be elaborated on by conscious thought, and math may involve fast and automatic recognition. Acknowledging that many real tasks can be performed by a combined effort of Type 1 and Type 2 processes also alleviates the critique that some automatic processes, such as driving, can also be controlled (Section 3.3; cf. Bargh, 1994). The Type 1 and Type 2 distinction ultimately leaves open the question of whether other types of processes may exist (Evans, 2008).

\section{I. Architectural features}

There are broad architectural differences between Type 1 and Type 2 processes. Type 1 architecture is massively parallel, based in the recurrent networks of the brain's approximately 86 billion neurons (Azevedo et al., 2009), which form a dynamical system (Freeman, 2000). They function associatively through the pickup of statistical regularities in inputs. Similarity and 
temporal order are particularly salient elements of these regularities (Sloman, 1996). Things that look alike or that are temporally contiguous will typically become associated with one another. Such associations are the basis of the prototypes and stereotypes that guide much of human cognition.

This parallel architecture allows for a rapid processing speed. We can contrast this with a simplified GOFAI (Good Old-Fashioned Artificial Intelligence) system based on serial, symbolic computation, which might recognize a bird by iteratively posing a series of questions:

Does it have a beak?
YES
Does it have wings?
YES
Does it fly?
YES
Then it is a bird.

This is a slow and cumbersome way to activate concepts, most of which have fuzzy borders anyway. It is much faster to recognize a bird by allowing incoming visual information to pass spreading activation across distributed nodes for beak, wings, and flying, thereby activating a prototype or concept. Whereas the symbolic approach iterates one step at a time, these nodes may be activated in tandem. When several distributed nodes are activated, the prototype or concept is activated. Such automatic, spreading activation is the reason why advertisers can expect viewers to automatically take the person in a medical coat selling toothpaste as trustworthy: the concept of a medical doctor is activated by visual information, but that activation spreads to other nodes of the concept, like trustworthiness. It takes effortful, propositional thought to actively veto those automatic associations (Devine, 1989). ${ }^{1}$

By contrast, Type 2 processes are inherently unified by their utilization of working memory (Carruthers, 2015; Evans \& Stanovich, 2013), a function associated with the prefrontal cortex and basal ganglia, among other regions (Kriete et al., 2013). For example, Goel et al. (2000) showed that although different forms of syllogistic reasoning (a predominantly Type 2 task) recruit different brain regions, they nonetheless share a common basis in the basal ganglia, left prefrontal cortex, and other areas associated with working memory. This foundation in working memory means they are often at least partly conscious processes (Carruthers, 2015; Faghihi et al., 2015). Type 1 processes, however, do not share a common basis in working memory or any other system, and they are not paradigmatically conscious processes.

Type 2 processes are based in the same parallel architecture of the brain, but they lead to seriality at a behavioral level. They are a kind of emulated or virtual machine running on the parallel architecture of the brain (Dennett, 1991). Enumerating things one by one, speaking words in a sentence, or progressively monitoring one part of a scene to another are examples of the behavioral seriality of Type 2 processes. Furthermore, different Type 2 processes cannot execute at the same time; at most, they can timeshare or multitask. This behavioral seriality is a constraint of the working memory that they must all pass through. Type 1 processes, however, are both neurally and behaviorally parallel. Multiple Type 1 processes can execute simultaneously because they are autonomous instead of controlled by attentional processes (like working memory's "central executive"; Baddeley, 2007).

Relative to the parallel Type 1 processes, Type 2 processes are highly constrained in their speed. The syntactical processing of speech production, subvocalization, planning, rational thought, mathematics, formal logic, and other rule-based processes is all functionally serial in nature. For example, you are reading this sentence word-by-word, from left to right, and it is not possible to read it en bloc. That is fundamentally different from how we perceive birds or any other prototype, which is en bloc rather than sequential. We may note that in some cases of expert judgment, judgments can also be very fast (Bargh, 1994). But this may be indicative that the judgments themselves arise not from Type 2 processes, like the nonexpert, but have become automatized or based on pattern-recognition, as with chess masters (Kahneman, 2011).

Serial processing creates a bottlenecking of system resources around the serial operation, a phenomenon known as the "von Neumann bottleneck" (see Figure 1). The seriality, in this case, is behavioral rather than strictly neural. Even if multimodal information is available all at once, it can only be processed one at a time in working memory-despite the parallelism of its neural underpinnings. The von Neumann bottleneck results in slower processing, essentially because other items must wait for their turn. It is like a traffic jam caused by only one lane being opened while the others are undergoing repairs.

Unlike the virtually limitless capacity of long-term memory, working memory has a far more limited capacity (Cowan, 2016). Consider the following paradox. We can seamlessly drive, field balls, or hike through a winding path. The best artificial intelligence of the early 21 st century is only beginning to match these capacities, and they require vast computational resources. And yet, a humble calculator can beat us at simple mental math. The dual-process answer to this paradox is that mental math is constitutively a different kind of cognitive process, one utilizing the limited resources of working memory and subject to the von Neumann bottleneck. But what we lose in speed, we gain in power, as mathematical cognition can potentially solve for any novel combination of symbols. 


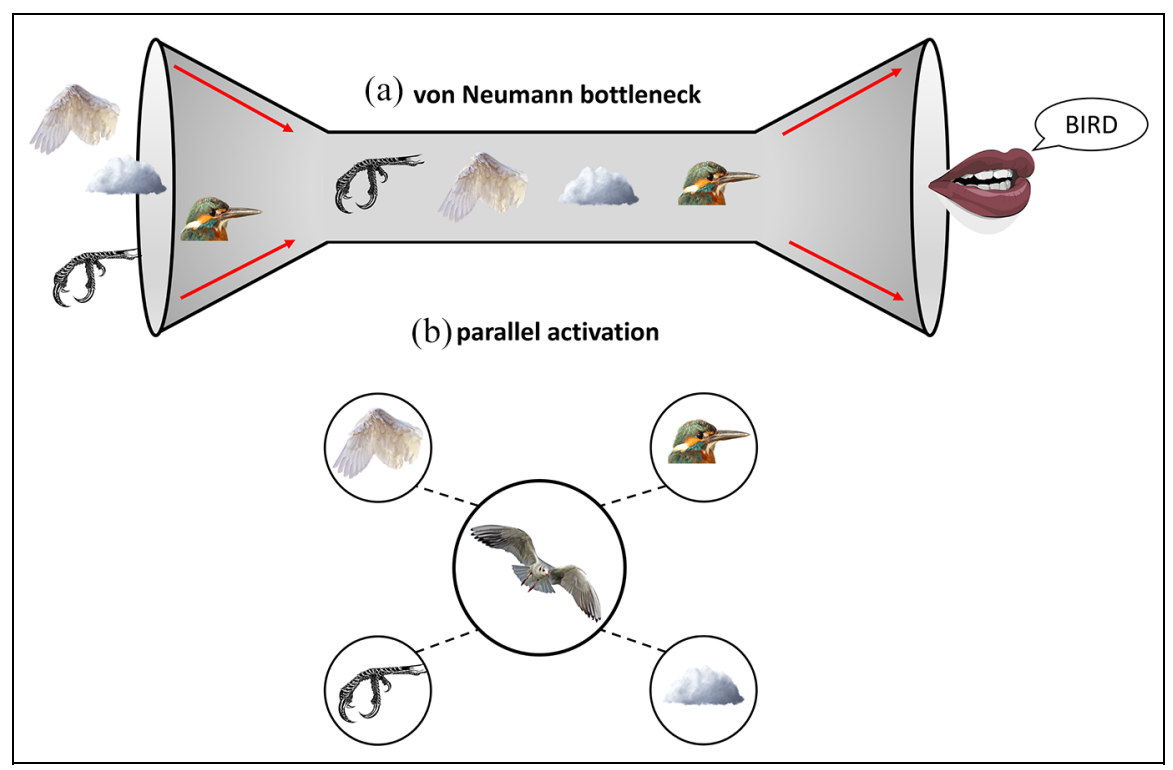

Figure I. (a) Serial processing creates a von Neumann bottleneck. In this example, different aspects of a bird are processed serially, resulting in an identification of "bird": "It has a beak, it's in the sky, it has wings, and it has claws. It must be a bird." While this is an inefficient route to object categorization, it is absolutely essential in linguistic, mathematical, and logical thought, such as in the equation " $7 x+1=35$," or even in controlled, conscious attention (Baars, 1988). (b) Parallel processing, as in connectionist networks, involves a spreading activation across distributed nodes, all operating simultaneously. Different feature nodes pass spreading activation to the concept "bird" all at once. No von Neumann bottleneck is created.

Many Type 2 processes are often capable of being subjected to standards of normative or discursive reasoning. These norms are established within institutions and communities and include rules of logic, inference, induction, mathematics, and discourse. Violations of these norms can be discovered by applying a rule, such as grammar. Regarding Type 1 processes, there are two views. Many consider them to be irrational, particularly because they are often associated with biases in reasoning (Kahneman, 2011). However, it would be hard to understand why humans would have evolved cognitive mechanisms that were outright "irrational" unless they confer some adaptive advantage. Indeed, Type 1 processes produce the right results most of the time. For example, making a Type 1 automatic, intuitive association between wearing a suit and being wealthy will often be right, even though there are other cases where the association will prove incorrect. But what does "the right results" mean in this context?

We can understand Type 1 processes as manifesting a form of instrumental rationality, which is achieved by pursuing goals in a suitable manner (Evans, 2007; Evans \& Over, 1996). Communal norms may guide this instrumental rationality, but they are unwritten norms of practice rather than codified rules. Although they are rule-describable, they are not rule-based (see Franklin, 1995). Furthermore, a proper means-ends relationship must hold, which is also a normative standard. To avoid confusion, I will refer to Type 2 processes as having discursive rationality (i.e., when they do fulfill this criterion). If the agent's goal is epistemic, then Type 1 processes may prove faulty, just as those who claim Type 1 processes are "irrational" might claim. But agents' primary goals in life are not epistemic but rather pragmatic. Agents are oriented toward action in an environment full of affordances. If the agent's goals are pragmatic rather than truth-oriented, then the intuitive association between wearing a suit and being wealthy will often be good enough (for example). The association can help facilitate social interaction according to social scripts and social affordances. Type 1 processes are only "irrational" if we don't consider the agent's pragmatic orientation in the world (something which my Heideggerian interpretation of dual-process theory will emphasize; Section 3.2).

\section{Smooth coping}

The term "smooth coping" is a more recent coinage, but it refers to Merleau-Ponty's (1945/2012) phenomenology of the body and, ultimately, to Heidegger's (1928/ 2010) phenomenology of Zuhandenheit. Translated as "readiness-to-hand" or "handiness," Zuhandenheit refers to the pervasive, pragmatic disposition with which a human agent approaches the world. Heidegger picks out Zuhandenheit to note that this pragmatic mode is often elided in theoretical accounts of human existence, where Vorhandenheit ("presence-at-hand" or "objective presence") is considered paradigmatic of human cognition. Vorhandenheit is a theoretical mode of 
approaching the world, characteristic of the modern project of science, particularly in the wake of Galileo, Locke, and Kant, particularly manifest in discursive rationality.

On H. L. Dreyfus' (2005, 2007a, 2007b, 2013) influential view, Zuhandenheit involves smooth coping through sensorimotor skills and embodied action, modeled on Aristotelian phronēsis. Aristotelian phronēsis is a practical wisdom based on situational factors. Unlike theoretical reason, it is largely learned through indirect training and upbringing. It is a practice rather than a theoretical attainment. It forms a bulk of skillful human action, such as walking and driving, but this action is "mindless," meaning that it is nonrational. Dreyfus pits his claims against McDowell (2007a, 2007b, 2013), who argues that phronessis as embodied action is pervaded with conceptual structures rather than divorced from them.

In Dreyfus' view, which he attributes to Heidegger, rationality and concepts are more limited in scope to theoretical and discursive practices:

Heidegger points out that most of our activities don't involve concepts at all ... Indeed, in our everyday coping, which he calls "pressing into possibilities," we don't deal with objects with general properties like weight, nor with situation-specific aspects like too heavy. Rather, when everything is going well and we are absorbed in our coping, the equipment we are using "withdraws" ... Then there is no place for a demonstrative concept pointing out our equipment as anything. We do not attribute a general property or even a situation-specific aspect to it; we just cope. (H. L. Dreyfus, 2007a, pp. 371-372)

Dreyfus' interpretation of Heidegger has been subject to several critiques. First, Dreyfus tends to identify smooth coping with expert performance and states of flow in sport. Yet Heidegger does not focus on levels of skill, and Zuhandenheit applies equally to "the skills needed to go through a door, write a letter, or sit down in a chair" (Breivik, 2007, p. 123). This seems to be a point H. L. Dreyfus (2013) later concedes, however, when he notes that walking is a form of smooth coping. My discussion of smooth coping takes this critique seriously and considers a wide range of embodied action beyond expert performance. And, as Breivik notes, just because we perform something regularly does not necessarily mean we gain mastery.

I argue that smooth coping primarily consists of Type 1 processes (although in some cases, particularly in Dreyfus' examples of expert action, Type 2 processes also contribute). Using Heidegger's phenomenology of calculation, understanding, and interpretation, I will argue for the interpretation of Type 1 not as irrational or nonrational, but rather as evincing an embodied rationality.

In Being and Time, Heidegger (1928/2010) develops a phenomenological account of Dasein, which is roughly embodied existence from a first-person perspective. ${ }^{3}$ Dasein has two fundamental modes of engaging with the world based on its care (Sorge), its affective and motivational structure. One mode is pragmatic and prereflective, meaning that it is more primordial to intellectualized reflection. Heidegger calls this mode "circumspection" (Umsicht). In circumspection, agents encounter things in the world as handy or ready-to-hand (zuhanden). Heidegger identifies this mode with Aristotelian phronessis and calls the things we encounter in it "equipment" (Zeug).

For Heidegger, equipment is an ontological category that differs from objects insofar as it has an inherently referential structure. Objects for Heidegger are contemplated through the detached, scientific mode of reasoning (Vorhandenheit). In this mode, objects are considered independent and self-standing; for example, a gold bar is just the collection of its properties of hardness, mass, and reflectance. Equipment, however, is not independent but always refers to some action; for example, a gold bar is a thing I use to exchange for money. It is the same gold bar in both examples, but the difference is how I comport myself to it. As an "object" (in Heidegger's language), the gold bar is an object of theoretical or scientific inquiry, while as equipment it is used for something. In circumspection, everything is encountered as equipment. Heidegger's point is that we do not primarily engage with the world through theoretical reason.

For example, a hammer is useful for hammering, that is, it is handy (zuhanden). A hammer can be approached circumspectly in terms of its affordances. It affords picking up, holding, swinging, and hammering. We encounter the hammer in terms of its affordances when we are engaged in practical activities, and the tool becomes part of a pragmatic network of other equipment useful for fulfilling a goal or intention. However, "[w]hen we look at things 'theoretically,' we lack an understanding of handiness [Zuhandenheit]" (p. 69). When we approach the hammer in terms of its brute material attributes (e.g. it weighs $1 \mathrm{~kg}$, it is made of wood and steel), we no longer approach it in terms of its affordances. This is the approach of Vorhandenheit.

Zuhandenheit is mostly identified with embodied, smooth coping. This is the basic, preconceptual level of Zuhandenheit, but Heidegger also claims there is a derivative mode of Zuhandenheit that is still a pragmatic form of phronessis, but which involves propositional thought. This derivative level of Zuhandenheit is what I will characterize as a hybrid Type 1-Type 2 situation. 
The basic level of Zuhandenheit is not propositional and can be characterized as mediated by affordances. I will argue this basic level predominantly consists of Type 1 processes.

This interpretation conflicts with Stuart Dreyfus' (2014) embodied dual-process theory, according to which smooth coping constitutes a System 0 - or, to maintain consistency with the terminology used in this article, "Type 0"- separate from Type 1 and 2 processes. Stuart Dreyfus claims that, unlike intuitive, Type 1 judgments, Type 0 processes are not judgments and are based in a neurologically separate habitual, striatal memory system from the declarative memory of Type 1 and Type 2 processes. Yet, I will argue that smooth coping does not significantly differ from other Type 1 processes. It satisfies the criteria for Type 1 features and correlates (see Table 1). These criteria are based on Evans and Stanovich (2013), but replace biased responses with embodied rationality (Evans \& Over, 1996).

Smooth coping

1. doesn't require working memory and is autonomous (Section 3.1),

2. manifests embodied rationality (rather than biased responses) (Section 3.2),

3. is parallel and high capacity (Section 3.3),

4. is fast and largely nonconscious (but may manifest prereflective consciousness) (Section 3.4), and

5. is contextualized and associative (through sensorimotor attunement) (Section 3.5).

Of the criteria above, those listed in Numbers 2 to 5 are typical correlates, and so their presence in smooth coping is not an absolute mark of being a Type 1 process, as the conditions in Number 1 are. However, by showing that both the necessary conditions and the typical correlates of Type 1 processes are evinced in smooth coping, I aim to make a stronger and more convincing case. Furthermore, I aim to identify idiosyncratic elements that follow from a Heideggerian approach to dual-process theory, particularly concerning embodied rationality, prereflective consciousness, and sensorimotor attunement.

\section{I. Working memory and autonomy}

The two central defining features of Type 1 processes is that they don't rely on working memory and are autonomous. Based on these two criteria, Furley et al. (2015) argue that embodied skills are predominantly executed by Type 1 processes, and their defense can be extended to smooth coping more generally. Much of embodied action is procedural rather than declarative:

Retrieving procedural knowledge does not require the same amount of controlled attention as declarative knowledge ... [A] highly practiced soccer player does not need to attend to the execution of dribbling the ball, which allows him to utilize his freed attentional resources for other aspects of the sport, such as scanning for open team-mates. (Furley et al., 2015, p. 114)

Controlled attention is a feature of working memory, something Baddeley (2007) calls the "central executive." The central executive directs attention to elements in the visuospatial sketchpad and the phonological loop, that is, to the visual and auditory modalities. This attentional direction is necessary to sustain focus and prevent the diversion of attention to other salient features and affordances in the environment. For example, sitting in a café and planning out a vacation requires that one be not continually distracted by ambient sounds, lights, and other people.

But embodied skills (and smooth coping more generally) often do not require such sustained attention (Furley et al., 2015), at least for mundane skills. Walking, for example, is mostly executed without much controlled attention at all. Some expert performance does involve intense attention, but I will discuss these as cases with mixed Type 1 and Type 2 processes in Section 3.3. Walking, driving, typing, and many other mundane embodied skills are correlatively autonomous, given that they do not require working memory to function (at least, for the experienced person). Indeed, the autonomy of different embodied actions is one reason why H. L. Dreyfus $(2005,2013)$ contends that smooth coping is "mindless"-it doesn't require focused attention or thought. Smooth coping typically operates in the background of awareness, and when embodied action does become the object of attention and reasoning, it often loses its speed and fluency.

\subsection{Biased responses and instrumental rationality}

Biased responses are a typical indication of Type 1 processes and are a mark of irrationality. If smooth coping is a Type 1 process, as I argue, then that would seem to strengthen Dreyfus' case for it being "mindless." Yet, it is not clear what a biased response would even mean in the context of embodied action. As an attribute, "biased response" make sense when we are studying reasoning (Wason \& Evans, 1974) or stereotypes (Devine, 1989), but is of little use when we are studying embodied action. However, this problem disappears if we replace that criterion with that of instrumental rationality, as opposed to the discursive rationality of Type 2 processes (Evans, 2007; Evans \& Over, 1996). As I previously argued (section 2.1), considerations of bias and irrationality assume a paradigm with an epistemically oriented agent. But if we instead regard the agent as action-oriented, then Type 1 processes rather manifest an instrumental rationality, pursuing an adequate means to an end. 
One of the central thrusts of Heidegger's (1928/2010) Being and Time is undermining the view of agents as essentially epistemic agents. For Heidegger, people are not primarily "knowers," but rather "doers." This is one of the primary roles that Zuhandenheit plays in that text. Vorhandenheit is the theoretical or epistemic orientation, but Heidegger claims that our basic experience of the world is not in the domain of Vorhandenheit. We are primarily pragmatic beings, seeking goals according to our cares or desires, and only secondarily are we knowers. Given this assumption, the appropriate Type 1 criterion is not bias but rather instrumental rationality (Evans \& Over, 1996).

According to H. L. Dreyfus (2007b), smooth coping in Heidegger is "non-conceptual, non-propositional, non-rational (even if rational means situation-specific) and non-linguistic" (p. 360). For Dreyfus, the field of affordances in coping "works in the background to make rationality possible, but the system of solicitations is not itself rational" (p. 358). Dreyfus criticizes McDowell for claiming that rationality is pervasive within coping and accuses him of mistaking the ability to retrospectively give reasons for an action with the rationality of that action itself. This is a category mistake, concludes H. L. Dreyfus (2007a): just because conceptual capacities can be exercised at any time, it does not mean they actually are operative.

There are several reasons to think that smooth coping is quite rational. Heidegger describes Dasein as doing "calculation" (Berechnung) for spatial relations. However, Heidegger distinguishes between two forms of spatial calculation: a theoretical and geometric approach, and a circumspect calculation (umsichtige Berechnung) (pp. 108-112). The theoretical approach to spatial calculation grasps spatial relations geometrically. This is the space of Kantian outer intuition or of mathematics. However, the circumspect calculation of spatial relations grasps equipment in terms of how near or far it is. This nearness or farness is not a distance as measured in meters but is a practical sense of how much time and effort it will take me to get to there. In other words, it is action-oriented. One example of circumspect spatial calculation is while walking uphill, I sense that the peak of the hill is far. Far is a relative term. The smooth coping operating in this situation relates to my previous experiences of walking to get the sense of farness and factors in my current and anticipated fatigue.

Furthermore, one of the Dasein's fundamental (existenzial) structures is understanding. Typically, understanding is something we would conceive of as a higher-order and symbolic propositional understanding. But for Heidegger, such propositional understanding, which may generate statements and language, is a "derivative form" (pp. 149-154). It is derivative of understanding as a fundamental existential structure, which is a form of know-how. "In understanding as an existential, the thing we are able to do is not a what, but being $\ldots$ as existing" (Heidegger, 1928/2010, pp. 139-143). Heidegger explains that understanding is grasping the possibilities of Dasein and of the world. "What is at hand is discovered as such in its serviceability, usability, detrimentality" (pp. 140-144). That is, understanding is the grasping both of affordances and of the agent's corresponding embodied capacities. Understanding is realized as a project, wherein Dasein projects itself into the world and achieves particular aims. Smooth coping involves an understanding that is directed toward projects, that is, that is goal-oriented.

Understanding is the basis of interpretation. As a derivative mode of Zuhandenheit, interpretation can involve basic propositional reasoning about useful things in the environment. And a full-blown interpretive project may quite heavily involve Type 2 processes. But as with understanding, interpretation is also a basic structure of Dasein and smooth coping. The agent does not have a pure, unmediated perception of the world, as in pure sense data that are subsequently interpreted. Instead, they perceive and understand within a holistic context, and their perception is always already interpreted. All perception and action, according to Heidegger (1928/2010), is interpretive:

The circumspect, interpretive dealing with what is at hand in the surrounding world which "sees" this as a table, a door, a car, a bridge does not necessarily already have to analyze what is circumspectly interpreted in a particular statement. Any simple prepredicative seeing of what is at hand is in itself already understanding and interpretive. (pp. 144-149)

For Heidegger, we do not see splotches of red and green color, but we see a red rose. It is the splotches of color that are an abstraction from our immediate experience. The holistic context in which I realize my possibilities and projects is not pregiven but is interpreted based on my past experiences, enculturation, and goals. Interpretation is based on understanding, and like understanding, its derivative mode can be used to generate statements and language, but it is not fundamentally propositional in format (pp. 140-144).

Accordingly, for Heidegger, smooth coping involves calculation, understanding, and interpretation. Coping is calculating insofar as it determines action-oriented spatial relations. It has understanding insofar as it grasps affordances and capacities for action according to projects or goals. And it interprets insofar as all sensorimotor action and perception are always already interpreted according to a holistic context. These three capabilities all have corresponding propositional modes, as when Dasein measures distances, understands a statement, or interprets a text. But these are derivative of the fundamental structures of Dasein. 
Dreyfus' interpretation of Heidegger on smooth coping is deficient on two points. First, he does not distinguish low-level Zuhandenheit from hybrid forms of Zuhandenheit. Second, he insists that the lower-level smooth coping is nonrational, essentially because he understands rationality as essentially Type 2 discursive rationality. Yet if our paradigm is action-orientation, we are no longer assuming a primarily epistemic agent. The criterion of bias and irrationality should be replaced with that of instrumental rationality. And Heidegger's discussion of smooth coping's calculation, understanding, and interpretation all are ways that an agent achieves its goals in a suitable manner-hence, coping is smooth.

Our ability to interact with affordances is based on learning sensorimotor patterns associated with very particular environmental and stimulus conditions. These sensorimotor patterns satisfice in the right environmental conditions. That is, they get the job done, but as patterns of action, they are inflexible and unable to adapt rapidly to novel conditions without training. Sensorimotor attunement is always to specific environments, and we lose that attunement as we find ourselves in new environments. For example, being a good driver under normal conditions does not transfer to driving on an icy road. The conditions differ just enough to make the sensorimotor skills possibly fail. Sensorimotor patterns are not rule-based but instead are designed to work well in the right situations. On the contrary, if we understand the rules of formal logical derivation, we ought to be able to solve problems we have never seen before.

We can more expansively call the instrumental rationality of smooth coping an "embodied rationality" to emphasize that the agent's accomplishment of its goals is fundamentally through sensorimotor engagement with the world. "Embodied rationality" has been invoked as a way to explain that apparently "irrational" biases in human thought make sense when we understand their bases in human embodiment (Spellman \& Schnall, 2009). According to Gallagher (2015, 2018), embodied rationality generates a rational structure in action and in the world, which he exemplifies with the human hand. In reaching out to grasp an object, the hand close-to-automatically "(and without the agent's conscious awareness) shapes itself into just the right posture to form the most appropriate grip" (Gallagher, 2018, p. 88). In Gallagher's (2015) view, embodied rationality manifests when the body copes with the world with appropriate forms of grip:

If I reach to grab an apple in order to take a bite, the shape of my grasp is different from when I reach to grab a banana, but also different from when I reach to grab the apple to throw it. (p. 139)
As Rolla (2021) states it, embodied rationality (or what he calls "Radically Enactive Rationality") is when "an organism acts rationally insofar as it maintains a proficient interaction with its environment, coordinating its cognitive abilities according to environmental constraints" (p. 7). But proficient interaction with the environment alone is not sufficient to indicate rationality. Consider the psychopathological case of alien hand syndrome, where a hand can be experienced as not under one's control. The hand still operates through smooth sensorimotor engagement, but it is no longer achieving the agent's goals. We would be hard-pressed to call this process "rational." What needs to be added to Rolla's definition is that it is proficient for achieving the agent's goals, making it a form of instrumental rationality. The hand that reaches out to grasp the apple in the right way is accomplishing the agent's goals. The "right way" is contingent upon not only the individual's capacities and the situational constraints but also upon the agent's goals. For example, if my goal is to eat the apple, and it is right on the table before me, then I may grab it in such a way to facilitate eating. But if my goal is to throw it, I may grab it and wind it back in preparation to throw it. Embodied rationality just is an instrumental rationality that is fulfilled through embodied, action-oriented means. Although smooth coping may not evince biased responses (as a typical Type 1 correlate), that criterion assumes that an agent is primarily epistemically oriented. But if we assume a primarily action-oriented agent (as Heidegger supports), then the salient Type 1 criterion is instrumental rationality rather than bias (Evans, 2007; Evans \& Over, 1996)-something that smooth coping does evince.

\subsection{High capacity and parallel}

Smooth coping is not sequential and does not function through rules, procedures, language, logic, or serial attention. During smooth coping, multiple sensorimotor processes can operate in parallel to create an emergent behavioral totality. The relevant sense of parallelism here is behavioral, engaging in multiple activities in tandem. For example, an expert driver effortlessly turns the steering wheel, visually scans the road, presses the brake and gas pedals, monitors the instrument panel, and uses turning signals. Steering and scanning the road involve different sensory modalities, different motor processes, and different brain regions. They can be performed in tandem without a hit to performance. These embodied processes are high capacity, far exceeding what can be held in the contents of working memory. 
Not only can the expert driver steer the wheel, regulate the pressure on the gas pedal, and scan the road all at the same time. Driving skills are largely performed unconsciously, at least for the expert driver. This does not mean that the driver is unconscious, but that most of the sensorimotor adjustments and skillful actions they perform while driving do not require working memory and are mostly unreportable. In addition, expert drivers can simultaneously engage in a conversation while driving. However, this does not make conversation another Type 1 process. Conversations are a complex case, involving both Type 1 and Type 2 processes. At the level of the propositions themselves, conversations are slow, linguistic, sequential, follow grammatical and Gricean norms, and hence strongly involve Type 2 processes. Furthermore, they are performed quite consciously, with subjects being able to report on their own sentence constructions. Type 1 processes are still involved in conversation, as conversing involves gesticulation, tonality, and other non-linguistic factors (see Gallagher, 2017), but the linguistic aspects more heavily involve Type 2 processes.

In the case of driving and talking, Type 1 and Type 2 processes can be engaged simultaneously without a significant performance hit to either. However, Type 2 processes are behaviorally serial and can only be performed one at a time. At best, one can switch rapidly between two Type 2 tasks ("multitasking"). ${ }^{4}$ While ordinary driving principally engages Type 1 processes, driving in heavy traffic additionally engages Type 2 processes, utilizing working memory resources in order to engage in a higher-order monitoring of smooth coping. Once a driver hits heavy traffic, fluent conversation cannot continue without higher-order monitoring and reasoning about the situation taking a performance hit. We can infer from this that driving in heavy traffic and conversing are competing processes to the extent they engage Type 2 processes. Namely, they compete for the resources of working memory and attention. As we know, working memory capacity is quite small (Cowan, 2016), and Type 1 processes do not utilize its resources. Compared with the limited resources of working memory, Type 1 parallel processing is very high bandwidth and can juggle multiple demanding sensorimotor processes simultaneously. There is no competition for resources or performance hits when we drive in normal conditions and hold a conversation because the processes underlying these two actions are fundamentally different.

Dreyfus' view, however, yields distinctly different hypotheses. According to Dreyfus, smooth coping is disrupted by propositional and reflective thinking, whereas on our model, these are not competing processes. "I grant that, when we are absorbed in everyday skillful coping, we have the capacity to step back and reflect but I think it should be obvious that we cannot exercise that capacity without disrupting our coping"
(H. L. Dreyfus, 2007b). In Dreyfus' view, reflective processes (Type 2) should interrupt our smooth coping. H. L. Dreyfus (2007a) claims that even something as basic as walking can be disrupted by reflective consciousness (p. 373).

Gallagher recalls an encounter with Dreyfus, who claimed that for the skier

[t]he presence of a reflective (thoughtful) element necessarily disturbs the expert performance. I offered my own response to this, which was that I thought expertise would include knowing when to reflect, and how to reflect, and what to think about in terms of anticipating changes in snow texture. (Gallagher, 2015, p. 136)

Several authors have mounted similar critiques of Dreyfus' model. It makes athletes "almost like zombies when they move around" (Breivik, 2013, p. 96). Montero (2015) argues that cases in which performance does diminish due to reflection may be because the subjects do not know what to reflect on properly. But, as in the Gallagher quote above, the expert would know precisely when, how, and on what to reflect. And that reflection may not necessarily be about the environment - it may even be about one's own body (Toner et al., 2016).

Our dual-process model explains how it is possible to simultaneously drive and be engaged in a conversation, or simultaneously walk and reflect, which would be puzzling on the Dreyfusian account. Høffding's (2019) critique of Dreyfus focuses on the stark dualism of his account: either smooth coping or reflection and reasoning is in force, but not both. And Breivik (2007) worries that dividing smooth coping into something achieved by two separate processes does not capture the breadth of nuances of Heideggerian Zuhandenheit. We can resolve this issue by recalling that Heidegger allows for a derivative level of Zuhandenheit where one can give reasons and yet still be engaged in smooth coping. In other words, we should identify smooth coping with the foundational level of Zuhandenheit, and a hybrid situation of smooth coping and Type 2 reflective processes with the derivative mode of Zuhandenheit. This nuance alleviates both Høffding's and Breivik's worries.

The kind of intense concentration we see in expert action is the hallmark of Type 2, not Type 1, precisely because conscious attention is a Type 2 correlate (which follows from working memory's central executive). Type 1 processes, however, are mostly unconscious and do not require intense attention, as with driving. That conscious attention operates serially and far more slowly than the smooth coping that it works in tandem with. The performer cannot simultaneously concentrate their attention on everything their body is doing, because attention cannot be spread in a parallel 
manner like that. They would attend to some highly salient feature, while smooth coping handles everything else. For example, the skier may attend to the look of the snow or to the slope gradient, reason about changes in gradients, and anticipate changes in the slopes, while their body semi-automatically makes microadjustments in posture and foot position. This monitoring and reasoning may very well be procedural or rule-based, and they allow for a limited planning, for example, anticipating a change in the slope ahead. It does not have to be as rapid as smooth coping because it is more narrowly focused.

If the expert performer were to switch suddenly to a different reflective task, this would most certainly disrupt their coping. However, that is because the expert performance relies on both systems, involving coping and reflective monitoring, and not because they were never reflecting to begin with, as Dreyfus claims. This is what happens when a driver hits heavy traffic, whereupon they will usually stop talking. They were using Type 2 processes and their working memory resources for conversation, and they now switch tasks to highlevel reasoning about the embodied situation. If they were to start conversing again, this would indeed disrupt their coping in the heavy traffic, but only because driving in heavy traffic is a skill that requires both systems (whereas driving in light traffic largely relies on Type 1 processes). On the dual-process model, starting to reflect where previously one was only coping would not disturb that coping, contra Dreyfus. This happens quite frequently, in fact, as with driving while talking or walking while thinking.

\subsection{Fast and nonconscious}

The parallel embodied processes of smooth coping are also fast, another Type 1 correlate. Smooth coping is rapid compared with more deliberate and controlled action. It involves ongoing and online microadjustments controlled in parallel through the motor cortices, cerebellum, motor ganglia, and muscles in interaction with the environment. The speed of its sensorimotor control is what allows it to outperform deliberative action, something that is particularly noticeable in expert action like skiing. When embodied movements become the objects of deliberate, Type 2 control, utilizing working memory, sensorimotor tasks become challenging and effortful. H. L. Dreyfus (2007b) gives the example of Chuck Knoblauch, a star baseball player who lost the ability to pitch well. According to Dreyfus, this loss of performance occurred because Knoblauch began interrupting his smooth coping by thinking about how to perform the action. In Section 3.3, however, we ruled out explanations to the effect that Type 2 processes interrupt Type 1 processes, at least in typical cases. In Knoblauch's case, our dual-process model would instead predict that the normal Type 2 reasoning is interrupted by a different Type 2 process (similar to Eysenck et al., 2007). Type 2 processes would normally monitor Knoblauch's baseball performance and intervene in coping in very limited ways. Instead, they likely became preoccupied with something else. Type 2 processes do not interrupt Type 1 processes by their mere presence, as Dreyfus claims.

Smooth coping is also largely nonconscious, another Type 1 correlate. This does not mean that the agent is necessarily unconscious while engaged in smooth coping, like a "zombie" (Breivik, 2013). Type 2 processes may be actively and consciously engaged in the situation, as well. Furthermore, smooth coping is often characterized by what phenomenologists call "prereflective" consciousness. Heidegger $(1928 / 2010$, pp. 74, 73) refers to circumspection as being "unthematic" or prepredicative. We are absorbed in the world, which is "already discovered beforehand together with everything encountered, although not thematically [unthematisch]" (pp. 81-83). Heidegger also refers to the theoretical or reflective mode as "thematic" (p. 75). "Theme" is a term from Husserl indicating the theme-horizon structure of phenomenal consciousness. Some object may be the theme of consciousness, and that theme is surrounded by a horizon of related but less clear things, or what William James (1890/1983) called the "fringe":

I was just now reflecting, when a whistle from the street momentarily distracts me from my theme (a theme I am thinking about here). I focus for a moment on the sound, but then quickly return to the old theme. My apprehension of the sound is not erased, I am still conscious of the whistle in a modified way, but it is no longer in my mental grip. (Husserl, 1913/2014, p. 243-254)

Heidegger invokes the Husserlian terminology, and equates the theoretical comportment with theme, and circumspection (smooth coping) with the unthematic. Heidegger (1928/2010) tells us that "handiness is ... understood, although not thematically [unthematisch], in dealing with what is at hand. It does not just disappear, but bids farewell, so to speak, in the conspicuousness of what is unusable" (pp. 73, 74). Something is conspicuous when it is grasped in the theoretical comportment. Handiness, and hence equipment grasped through their affordances, fades as equipment becomes a thematic object.

Heidegger (2005) explicitly characterizes "objects" as thematic. "'Object' means ... what stands opposite the 
mere observer who simply looks at it, what is present, after being thematically selected and had as such" (pp. 10-17).

Our everyday experience of things ... is neither objectifying nor a placing over against. When, for example, we sit in the garden and take delight in a blossoming rose, we do not make an object of the rose, nor do we even make it something standing over against us in the sense of something represented thematically. (Heidegger, 1998, pp. 58-73)

We appreciate the unthematic rose, but it is not a thematic object unless we abstract from it and approach it in terms of its "objective" properties, such as redness or being of a particular cultivar.

For Heidegger, the theme is that which is articulated in the theoretical comportment, especially through language. The unthematic is the field of affordances, and more broadly all action-oriented aspects of equipment, serving as a background to smooth coping, which Dasein "understands" and "interprets." "[B]eing-in-the-world signifies the unthematic, circumspect absorption in the references constitutive for the handiness of the totality of equipment" (translation modified; 2010, pp. 75, 76).

More recent phenomenological studies in expert performance further contend that the body itself is often apprehended in prereflective consciousness during skilled action (Toner et al., 2016). Prereflective awareness is not merely about external affordances but also about one's own kinesthetic states. Although our body may not always be the theme of consciousness, it is often in the unthematic horizon. For example, while walking, I often have a background awareness of my movements. Although I may not focus on my legs, it is not as if I were merely floating. And according to Høffding (2019), "Flow does not entail any loss neither of consciousness, nor of self, but rather a momentary break from or oblivion of that peculiar content in which the narrative self consists" (p. 137). In other words, although the performer in the flow may feel a loss of (narrative) self, this does not mean they lose consciousness.

Smooth coping is largely unconscious, but some of it may be prereflectively conscious. Note that this claim is more nuanced than the typical dual-process statement that Type 1 processes are nonconscious. We are not somehow blacked out when we engage in Type 1 processes. In coping, we may become prereflectively aware of the results of the sensorimotor processes involved, or have a sense of agency when accomplishing them. At the same time, the micromotor movements themselves remain outside conscious, intentional control. As Gallagher (2018) notes, the hand close-toautomatically opens in the right way for grasping a cup. I may not make my hand thematic, but I may be peripherally aware of it.

\subsection{Contextualized and associative}

In contrast with the seriality, rules, procedures, and syntax of Type 2 processes, Type 1 processes function as a neural net, with weighted connections between nodes and activation that spreads across them. Typically, this is indicated by calling Type 1 processes "associative." (While the same processes ultimately underlie Type 2 processes, they produce functionally emergent serial processes at the behavioral level [Carruthers, 2006; Dennett, 1991; Frankish, 2004] by virtue of the von Neumann bottleneck of working memory.) Many stereotypes, prototypes, and other cognitive tricks and shortcuts geared toward satisficing are based on such parallel networks. In the domain of embodied action, the relevant cognitive trick or shortcut is sensorimotor attunement. For example, in grabbing a cup, there is a stereotyped pattern of activation of the parallel central nervous, peripheral nervous, and muscular networks. The hand develops a sensorimotor attunement to the cup through a history of coupling with it. The hand does not follow rules or procedures. Instead, it operates through a spreading activation of networks in the motor cortices, cerebellum, motor ganglia, and muscles, networks that dynamically couple and adapt to some of the physical properties of the cup, its distance, the angle presented, and its size, generating its affordances.

Developing an embodied habit or skill in smooth coping requires plastic changes in the brain. Motor skills, for example, develop in the brain in two phases. First, a short-term, limited learning of specific movements is mediated by increased activation of a limited cortical network. Second, a long-term, consolidative learning of comprehensive sensorimotor patterns is mediated by a bilateral network involving both cortical and subcortical regions (Floyer-Lea \& Matthews, 2005; Ungerleider, 2002). Some embodied practices, such as sustained exercise, trigger neuroplastic changes with cascading consequences beyond skill performance itself, positively affecting long-term memory, processing speed, and cognitive health (Kramer et al., 2006). Embodied skills can also trigger other changes to brain physiology, such as by triggering angiogenesis or the production of new blood vessels (Isaacs et al., 1992).

Sensorimotor attunement in smooth coping is not limited to neuroplastic and other physiological changes to the brain, however. More expansively, sensorimotor attunement involves an "ongoing dynamical adjustment in which the brain, as part of and along with the larger organism, settles into the right kind of attunement with the environment - an environment that is physical but also social and cultural" (Gallagher, 2017, p. 17). Neuroplastic changes in the brain are complemented by changes in bodily physiology in the learning of embodied skills. For example, beginning weightlifters experience an initial rapid gain in strength, which later slows 
down. This phenomenon is not simply an effect of strengthening muscles. It involves changes to how muscles contract under impulses from peripheral motor neurons, which increase their signaling strength and efficiency (Aagaard et al., 2002). Different forms and techniques of weightlifting (e.g. Olympic vs. traditional) result in the development of distinct patterns of activations of muscle groups across limbs and the body (Arabatzi \& Kellis, 2012), such that a weightlifter from one style will activate different muscle networks from a weightlifter in the other style. As the central nervous system attunes to particular patterns of peripheral nervous system activation in repetitive weightlifting tasks, peripheral ganglia, motor plates, and muscles also undergo changes in their activations and strengths. Weightlifting is as much a bodily attunement as it is a cerebral attunement to stereotyped patterns of activation in parallel networks. The consequence of this distributed activation and reshaping of neural and bodily pathways is that multiple embodied networks are engaged simultaneously at the behavioral level, as well. In weightlifting, a host of different muscles and limbs move in tandem to perform a lift and maintain balance.

As with all stereotypes, prototypes, and other associative tricks, sensorimotor attunement is always to very specific contexts, which in the weightlifting example are environmental and social. It also does not easily transfer to similar situations, as we would expect propositional knowledge to. This context-dependence is characteristic not only of the skill and habit memory systems that underlie sensorimotor attunement (Ennen, 2003) but also of the peripheral and bodily systems that also mediate it. When the Olympic weightlifter activates different muscles from the traditional weightlifter, this relates not only to their different movements and goals but also to their different equipment and social milieus. For example, Olympic squats basically involve a squat rack and a barbell with weights, with a few other implements. However, powerlifting squats, which involve much heavier weights (up to $500 \mathrm{~kg}$ or more), can additionally involve specialized clothing, joint wraps, catching belts, and a retinue of spotters doubling as motivators, not to mention "gear" (steroids). Not only do the Olympic weightlifter's and the powerlifter's techniques differ, but their environments yield different affordances. But change the powerlifter's environment, remove all that extra equipment (in "unequipped lifts"), and they will not be able to give the same performance due to the environmental specificity of sensorimotor attunement.

According to Varela (1999),

We always operate in some kind of immediacy of a given situation. Our lived world is so ready-[to]-hand [i.e., zuhanden] that we have no deliberateness about what it is and how we inhabit it. When we sit at the table to eat with a relative or friend, the entire complex know-how of how to handle our utensils, how to sit, how to converse, is present without deliberation ... We have a readiness-for-action proper to every specific lived situation ... I call any such readiness-for-action a microidentity and its corresponding lived situation a microworld. (pp. 9-10)

Sensorimotor attunement is essentially the generation of a microidentity within a microworld. We are composed of many microidentities, and we dwell across many such microworlds. By returning to Varela's Heideggerian inspiration, we can further specify that a microworld has a networked structure. According to Heidegger, equipment or Zeug has an inherently referential structure. "There always belongs to the being of a useful thing [Zeug] a totality of useful things in which this useful thing can be what it is. A useful thing is essentially "something in order to ..." (Heidegger, $1928 / 2010$, p. 68). In smooth coping, equipment is encountered as sets of affordances that are interconnected in a web of contextual relations, or an "involvement network" (Kiverstein, 2012, p. 4). For example, the gym is for the weightlifter a microworld, one replete with affordances for lifting, pulling, heaving, and squatting. The bench press affords lying down. The action of lying down, in turn, is for the sake of pushing the barbell away from the chest. Lying down and pushing the barbell upward are mutually referential affordances. Lying down without pushing the barbell is socially inappropriate, as the gym is not a place to relax or sleep. And pushing the barbell upward from the chest requires a supine position. Even the gym's water fountain is contextually related to the more physically taxing affordances around, as it helps sustain those strenuous actions by keeping the weightlifter hydrated. The gym as a whole forms an involvement network or what we are calling a microworld.

The weightlifter develops a microidentity, or a sensorimotor attunement, to the gym microworld through sustained practice over time, going beyond short-term motor learning to the long-term motor learning involving cortical and subcortical networks. Furthermore, the weightlifter's body transforms as peripheral ganglia, motor plates, and muscle networks adapt and attune to the embodied practices in this microworld, most visibly causing muscular hypertrophy. The weightlifter's embodied patterns of action in this microworld manifest an embodied rationality as they realize their goals through bodily performance.

Different microworlds require different sensorimotor attunements. As such, embodied Type 1 processes are a meshwork of piecemeal sensorimotor attunements that have arisen across the many microworlds the agent dwells and interacts within. Beyond the gym, the weightlifter may have different sensorimotor attunements to 
Table 2. General Type I features and correlates, and remarks on how they manifest in smooth coping.

\begin{tabular}{ll}
\hline Type I feature or correlate & Special remarks for smooth coping \\
\hline $\begin{array}{l}\text { features } \\
\text { working memory } \\
\text { autonomous }\end{array}$ & No primary use of working memory. \\
$\begin{array}{l}\text { correlates } \\
\text { biased responses/instrumental } \\
\text { rationality }\end{array}$ & $\begin{array}{l}\text { "Biased responses" assumes a symbolic or linguistic modality. Instrumental rationality may be a } \\
\text { parallel }\end{array}$ \\
$\begin{array}{l}\text { more general correlate. In smooth coping, this is equivalent to embodied rationality. } \\
\text { Thigh capacity } \\
\text { fast }\end{array}$ & $\begin{array}{l}\text { The parallel networks also involve the peripheral nervous system, muscles, and even extended } \\
\text { nonconscious } \\
\text { contextualized and associative }\end{array}$ \\
$\begin{array}{l}\text { Can perform multiple independent tasks. } \\
\text { Allowing it to outperform deliberative action. } \\
\text { But also, in part, prereflectively conscious. } \\
\text { In smooth coping, associative networks develop through sensorimotor attunement } \\
\text { to microworlds. }\end{array}$ \\
\hline
\end{tabular}

the car, home, university, work, bar, and so forth. Each of these microworlds has different involvement networks and hence different context dependencies.

Overall, embodied Type 1 processes have a set of features that are all consequences of weighted, spreading activation of neural nets: stereotypes, prototypes, and sensorimotor attunements. It just happens that sensorimotor attunements also involve extra-cerebral network connections to the peripheral nervous system, muscles, and microworld, whereas the other forms are comparatively more brain-bound.

According to Heidegger, smooth coping is disrupted through a shift from handiness (Zuhandenheit), to unhandiness (Unzuhandenheit), to objective presence (Vorhandenheit). The referential structure of equipment breaks down when one piece of equipment malfunctions and becomes conspicuous and unhandy. "Something is unusable. This means that the constitutive reference of the in-order-to to a what-for has been disrupted" (Heidegger, 1928/2010, p. 74). The conspicuous, unusable thing already breaks the microworld's referential structure, creating a gaping hole in the involvement network. A further reflective step back will further break the referential structure and bring forth an "object." The world of objective presence is a world replete with objects rather than affordances. Essentially, this is simply a shift in attitude or disposition; the environment itself has not somehow changed. A stark example is a weightlifter appraising a new gym, seeing its equipment in terms of their brands rather than in terms of their affordances.

But reflective thought and coping do not function by a binary switch, as if only one could be active at a given time. "Skill is not a matter of bypassing explicit thought, to let habitual actions run entirely on their own, but of building and accessing flexible links between knowing and doing" (Sutton et al., 2011, p.
95). For example, a weightlifter may engage in a higher-order monitoring of and reasoning about their technique or form as they perform a squat. As they move with the barbell, they will look in the mirror to judge and correct their form according to the weightlifting community's normative standards. The weightlifter's kinesthetic and skillful movements are unthematic, meaning that they are achieved largely unconsciously (through the body schema) but that their results are available for prereflective awareness (e.g. the weightlifter feels their body moving under strain). They are simultaneously engaged in a higher-order monitoring of and reasoning about their body through their body image in the mirror. This monitoring of the mirror body image is thematic, meaning it occupies the center of conscious attention, contrary to the peripheral awareness of the body schema. As thematic, the weightlifter can subject their mirror body image to judgments, judging their form in a way that abstracts from their immediate coping and microworld and involving working memory resources, either visuospatial or phonological. In other words, they will use mental imagery or propositional rules to judge and correct their form. As the theme of judgment, their body image is taken as a token of a type of squat, and they can apply mental simulations as well as propositional rules to decide whether their token form matches the ideal type. As they step back from their immediate situation by engaging in normative judgment, the weightlifter is attitudinally disposed to their body image as an objectively present (vorhanden) object. The reflective judgment is a form of disattunement from their microworld, as it involves propositions, symbols, and mental simulations of forms that are abstracted from this singular microworld. Yet, all the while they continue in their embodied coping as they perform the squat. Type 1 sensorimotor attunement continues while the reflective, 
Type 2 processes simultaneously disattune from the immediate environment to impose procedural and rulebased standards on it.

\section{Conclusion}

Although dual-process theory was originally devised to explain biases in judgment (Wason \& Evans, 1974), it has since expanded into multiple domains, and embodied cognition is one of them (S. E. Dreyfus, 2014; Furley et al., 2015; Körner \& Strack, 2018; Petracca, 2020). The everyday, embodied action that pervades our lives is replete with Type 1 processes:

1. Smooth coping involves the defining features of Type 1 processes (autonomy and no necessary reliance on working memory) as well as of their typical correlates (instrumental rationality, high capacity and activation through parallel networks, rapid speed, nonconscious processing, and contextualized, associative mechanisms (see Table 2). (I have defended replacing biased responses with instrumental rationality.)

2. Therefore, smooth coping is composed primarily of Type 1 processes, although Type 2 processes can also play a role, such as in expert action.

There is no need to posit a new "Type 0" or "System 0" for smooth coping, as Stuart Dreyfus (2014) does. Smooth coping bears the same features and correlates of Type 1 processes, albeit with some special aspects whose uniqueness is related to their motor modality. For example, the associative networks that develop in smooth coping involve not only the brain but also the peripheral nervous system, musculature, and possibly even extended aspects of the environment, whereas for more conceptual Type 1 processes (such as an association between wearing a medical coat and trustworthiness) the primary locus is the brain.

Compared with Hubert Dreyfus' model of smooth coping, the embodied dual-process theory that I argue for yields distinctly different hypotheses. Dreyfus understands coping as a process that competes with executive control and predicts that it will be interrupted by executive control and propositional thought - not only in expert action (as with choking) but also in everyday tasks like walking. According to our embodied dual-process model; however, smooth coping and executive, higher-order reasoning are separate processes that do not directly compete for the same cognitive resources. Type 1 processes do not compete for working memory resources that are integral to Type 2 processes. Hence, the embodied dual-process model makes comprehensible phenomena like driving while talking, or walking while contemplating, something which would be unexplained in Dreyfus' model.

\section{Acknowledgement}

The author thanks Shaun Gallagher, Somogy Varga, Tom Nenon, and three anonymous reviewers for their insightful comments, which have strengthened this article.

\section{Funding}

The author(s) received no financial support for the research, authorship, and/or publication of this article.

\section{ORCID iD}

Zachariah A Neemeh iDhttps://orcid.org/0000-0001-70194662

\section{Notes}

1. Although this is the dominant dual-process interpretation of Type 1, see Mandelbaum (2016) for a critique of association in dual-process theory (in the context of implicit bias).

2. However, some forms of Vorhandenheit can be more basic and intuitive, for example, a Lockean perception of complex ideas (which is a kind of theoretical rather than action-oriented perception).

3. There is a significant controversy over whether Heidegger provides an embodied account (Aho, 2010). Heidegger never explicitly thematizes the body, yet his pragmatic account of action seems to require that Dasein be embodied. For the purposes of this article, I take the view that Heidegger's account of Dasein inherently assumes embodiment.

4. Type 1 processes are parallel because many of them can operate simultaneously. But Type 2 processes are serial because only one of them can operate at a time, due to the constraints of working memory, a resource they all share. It is true that they can operate "in parallel with" Type 1 processes, as the latter are independent of working memory, but the relevant sense of serial/parallel here is within the type itself.

\section{References}

Aagaard, P., Simonsen, E. B., Andersen, J. L., Magnusson, P., \& Dyhre-Poulsen, P. (2002). Increased rate of force development and neural drive of human skeletal muscle following resistance training. Journal of Applied Physiology, 93(4), 1318-1326. https://doi.org/10.1152/japplphysiol.00283. 2002

Aho, K. A. (2010). Heidegger's neglect of the body. State University of New York Press.

Arabatzi, F., \& Kellis, E. (2012). Olympic weightlifting training causes different knee muscle-coactivation adaptations compared with traditional weight training. Journal of Strength and Conditioning Research, 26(8), 2192-2201. https://doi.org/10.1519/JSC.0b013e31823b087a

Azevedo, F. A., Carvalho, L. R., Grinberg, L. T., Farfel, J. M., Ferretti, R. E., Leite, R. E., Filho, W. J., Lent, R., \& Herculano-Houzel, S. (2009). Equal numbers of neuronal and nonneuronal cells make the human brain an isometrically scaled-up primate brain. Journal of Comparative Neurology, 513(5), 532-541. https://doi.org/10.1002/cne.21974 
Baars, B. J. (1988). A cognitive theory of consciousness. Cambridge University Press.

Baddeley, A. (2007). Working memory, thought, and action. Oxford University Press.

Bargh, J. A. (1994). The four horsemen of automaticity: Intention, awareness, efficiency, and control as separate issues.

Breivik, G. (2007). Skillful coping in everyday life and in sport: A critical examination of the views of Heidegger and Dreyfus. Journal of the Philosophy of Sport, 34(2), 116-134. https://doi.org/10.1080/00948705.2007.9714716

Breivik, G. (2013). Zombie-like or superconscious? A phenomenological and conceptual analysis of consciousness in elite sport. Journal of the Philosophy of Sport, 40(1), 85-106. https://doi.org/10.1080/00948705.2012.725890

Carruthers, P. (2006). The architecture of the mind. Oxford University Press.

Carruthers, P. (2015). The centered mind: What the science of working memory shows us about the nature of human thought. Oxford University Press.

Chaiken, S. (1980). Heuristic versus systematic information processing and the use of source versus message cues in persuasion. Journal of Personality and Social Psychology, 39(5), 752. https://doi.org/10.1037/0022-3514.39.5.752

Cowan, N. (2016). Working memory capacity (Classic ed.). Psychology Press.

De Neys, W. (2017). Bias, conflict, and fast logic: Towards a hybrid dual process future? In Neys De, W. (Ed.), Dual process theory 2.0 (pp. 47-65). Routledge.

Dennett, D. C. (1991). Consciousness explained. Penguin.

Devine, P. G. (1989). Stereotypes and prejudice: Their automatic and controlled components. Journal of Personality and Social Psychology, 56(1), 5-18. https://doi.org/ 10.1037/0022-3514.56.1.5

Dreyfus, H. L. (2005). Overcoming the myth of the mental: How philosophers can profit from the phenomenology of everyday expertise. Proceedings and Addresses of the American Philosophical Association, 79(2), 47-65.

Dreyfus, H. L. (2007a). Response to McDowell. Inquiry, 50(4), 371-377. https://doi.org/10.1080/00201740701489 401

Dreyfus, H. L. (2007b). The return of the myth of the mental. Inquiry, 50(4), 352-365. https://doi.org/10.1080/002017 40701489245

Dreyfus, H. L. (2013). The myth of the pervasiveness of the mental. In J. K. Schear (Ed.), Mind, reason, and being-inthe-world: The McDowell-Dreyfus debate (pp. 15-40). Routledge.

Dreyfus, S. E. (2014). System 0: The overlooked explanation of expert intuition. In M. Sinclair (Ed.), Handbook of research methods on intuition (pp. 15-27). Edward Elgar Publishing.

Ennen, E. (2003). Phenomenological coping skills and the striatal memory system. Phenomenology and the Cognitive Sciences, 2(4), 299-325. https://doi.org/10.1023/B:PHEN. 0000007368.66888 .78

Evans, J. St. B. T. (2007). Hypothetical thinking: Dual processes in reasoning and judgement. Psychology Press.

Evans, J. St. B. T. (2008). Dual-processing accounts of reasoning, judgment, and social cognition. Annual Review of Psychology, 59, 255-278. https://doi.org/10.1146/annurev. psych.59.103006.093629
Evans, J. St. B. T., \& Over, D. E. (1996). Rationality and reasoning. Psychology Press.

Evans, J. St. B. T., \& Stanovich, K. E. (2013). Dual-process theories of higher cognition: Advancing the debate. Perspectives on Psychological Science, 8(3), 223-241. https: //doi.org/10.1177/1745691612460685

Eysenck, M. W., Derakshan, N., Santos, R., \& Calvo, M. G. (2007). Anxiety and cognitive performance: Attentional control theory. Emotion, 7(2), 336-353. https://doi.org/ 10.1037/1528-3542.7.2.336

Faghihi, U., Estey, C., McCall, R., \& Franklin, S. (2015). A cognitive model fleshes out Kahneman's fast and slow systems. Biologically Inspired Cognitive Architectures, 11, $38-52$.

Floyer-Lea, A., \& Matthews, P. M. (2005). Distinguishable brain activation networks for short- and long-term motor skill learning. Journal of Neurophysiology, 94(1), 512-518. https://doi.org/10.1152/jn.00717.2004

Frankish, K. (2004). Mind and supermind. Cambridge University Press.

Franklin, S. (1995). Artificial minds. MIT Press.

Freeman, W. (2000). Neurodynamics: An exploration in mesoscopic brain dynamics. Springer.

Furley, P., Schweizer, G., \& Bertrams, A. (2015). The two modes of an athlete: Dual-process theories in the field of sport. International Review of Sport and Exercise Psychology, 8(1), 106-124. https://doi.org/10.1080/1750984X.2015. 1022203

Gallagher, S. (2015). The practice of thinking: Between Dreyfus and McDowell. In T. Breyer, \& C. Gutland (Eds.), Phenomenology of thinking: Philosophical investigations into the character of cognitive experiences (pp. 140-152). Routledge.

Gallagher, S. (2017). Enactivist interventions: Rethinking the mind. Oxford University Press.

Gallagher, S. (2018). Embodied rationality. In G. Bronner, \& F. Di Iorio (Eds.), The mystery of rationality: Mind, beliefs and the social sciences (pp. 83-94). Springer.

Goel, V., Buchel, C., Frith, C., \& Dolan, R. J. (2000). Dissociation of mechanisms underlying syllogistic reasoning. NeuroImage, 12(5), 504-514. https://doi.org/10.1006/nimg. 2000.0636

Heidegger, M. (1998). Pathmarks. Cambridge University Press.

Heidegger, M. (2005). Introduction to phenomenological research. Indiana University Press.

Heidegger, M. (2010). Being and time (J. Stambaugh, \& D. J. Schmidt, Trans., rev. ed.). State University of New York Press. (Original work published 1928)

Høffding, S. (2019). A phenomenology of musical absorption. Springer.

Husserl, E. (2014). Ideas I (D. O. Dahlstrom, Trans.). Hackett. (Original work published 1913)

Isaacs, K. R., Anderson, B. J., Alcantara, A. A., Black, J. E., \& Greenough, W. T. (1992). Exercise and the brain: Angiogenesis in the adult rat cerebellum after vigorous physical activity and motor skill learning. Journal of Cerebral Blood Flow \& Metabolism, 12(1), 110-119.https: //doi.org/10.1038/jcbfm.1992.14

James, W. (1983). The principles of psychology. Harvard University Press. (Original work published 1890) 
Kahneman, D. (2011). Thinking, fast and slow. Macmillan.

Kahneman, D., \& Frederick, S. (2002). Representativeness revisited: Attribute substitution in intuitive judgment. In T. Gilovich, D. Griffin, \& D. Kahneman (Eds.), Heuristics and biases: The psychology of intuitive judgment (pp. 4981). Cambridge University Press. https://doi.org/10.1017/ CBO9780511808098.004

Kiverstein, J. (2012). What is Heideggerian cognitive science? In J. Kiverstein, \& M. Wheeler (Eds.), Heidegger and cognitive science (pp. 1-61). Palgrave Macmillan.

Körner, A., \& Strack, F. (2018). Embodiment: Reflective and impulsive processes. In G. Hauke, \& A. Kritikos (Eds.), Embodiment in psychotherapy (pp. 97-112). Springer.

Kramer, A. F., Erickson, K. I., \& Colcombe, S. J. (2006). Exercise, cognition, and the aging brain. Journal of Applied Physiology, 101(4), 1237-1242. https://doi.org/ 10.1152/japplphysiol.00500.2006

Kriete, T., Noelle, D. C., Cohen, J. D., \& O'Reilly, R. C. (2013). Indirection and symbol-like processing in the prefrontal cortex and basal ganglia. Proceedings of the National Academy of Sciences of the United States of America, 110(41), 16390-16395. https://doi.org/10.1073/ pnas.1303547110

Mandelbaum, E. (2016). Attitude, inference, association: On the propositional structure of implicit bias. Noûs, 50(3), 629-658. https://doi.org/10.1111/nous.12089

McDowell, J. (2007a). Response to Dreyfus. Inquiry, 50(4), 366-370. https://doi.org/10.1080/00201740701489351

McDowell, J. (2007b). What myth?Inquiry, 50(4), 338-351. https://doi.org/10.1080/00201740701489211

McDowell, J. (2013). The myth of the mind as detached. In J. K. Shear (Ed.), Mind, reason, and being-in-the-world (pp. 51-68). Routledge.

Melnikoff, D. E., \& Bargh, J. A. (2018). The mythical number two. Trends in Cognitive Sciences, 22(4), 280-293. https: //doi.org/10.1016/j.tics.2018.02.001

Merleau-Ponty, M. (2012). Phenomenology of perception (D. A. Landes, Trans.). Routledge. (Original work published 1945)

Montero, B. G. (2015). Thinking in the zone: The expert mind in action. The Southern Journal of Philosophy, 53, 126-140. https://doi.org/10.1111/sjp.12119
Pennycook, G., De Neys, W., Evans, J. S. B., Stanovich, K. E., \& Thompson, V. A. (2018). The mythical dual-process typology. Trends in Cognitive Sciences, 22(8), 667-668. https://doi.org/10.1016/j.tics.2018.04.008

Petracca, E. (2020). Two and a half systems: The sensorymotor system in dual-process judgment and decision-making. Journal of Neuroscience, Psychology, and Economics, 13(1), 1-18. https://doi.org/10.1037/npe0000113

Rolla, G. (2021). Reconceiving rationality: Situating rationality into radically enactive cognition. Synthese, 198, 571-590.

Samuels, R. (2009). The magical number two, plus or minus: Dual-process theory as a theory of cognitive kinds. In J. Evans, \& K. Frankish (Eds.), Two minds: Dual processes and beyond (pp. 129-146). Oxford University Press. https://doi.org/10.1093/acprof:oso/ 9780199230167.003.0006

Sloman, S. A. (1996). The empirical case for two systems of reasoning. Psychological Bulletin, 119(1), 3-22. https: //doi.org/10.1037/0033-2909.119.1.3

Spellman, B. A., \& Schnall, S. (2009). Embodied rationality. Queen's LJ, 35, 117-164.

Stanovich, K. (2011). Rationality and the reflective mind. Oxford University Press.

Sutton, J., McIlwain, D., Christensen, W., \& Geeves, A. (2011). Applying intelligence to the reflexes: Embodied skills and habits between Dreyfus and Descartes. Journal of the British Society for Phenomenology, 42(1), 78-103. https://doi.org/10.1080/00071773.2011.11006732

Toner, J., Montero, B. G., \& Moran, A. (2016). Reflective and prereflective bodily awareness in skilled action. Psychology of Consciousness: Theory, Research, and Practice, 3(4), 303-315. https://doi.org/10.1037/cns000 0090

Ungerleider, L. (2002). Imaging brain plasticity during motor skill learning. Neurobiology of Learning and Memory, 78(3), 553-564. https://doi.org/10.1006/nlme.2002.4091

Varela, F. J. (1999). Ethical know-how: Action, wisdom, and cognition. Stanford University Press.

Wason, P. C., \& Evans, J. St. B. T. (1974). Dual processes in reasoning?Cognition, 3(2), 141-154. https://doi.org/10.10 16/0010-0277(74)90017-1

\section{Author biography}

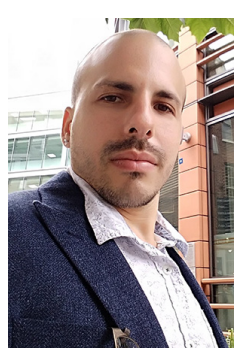

Zachariah A. Neemeh is a PhD candidate in philosophy and an affiliate of the Institute for Intelligent Systems at the University of Memphis. He is a member of the Cognitive Computing Research Group (CCRG), working on the development of LIDA, an embodied cognitive architecture implementing global workspace theory. His work focuses on the "mutual enlightenment" between phenomenology and cognitive science. 